Fixed Point Theory, 22(2021), No. 2, 511-526

DOI: $10.24193 /$ fpt-ro.2021.2.34

http://www.math.ubbcluj.ro/ nodeacj/sfptcj.html

\title{
EXTENSION OF $\lambda$-PIR FOR WEAKLY CONTRACTIVE OPERATORS VIA FIXED POINT THEORY
}

\author{
A. BELHENNICHE* ${ }^{*}$ S. BENAHMED* AND F.L. PEREIRA** \\ *École Nationale Polytechnique d'Oran Maurice Audin, \\ B.P 1523 El M'naouer Oran 31000, Algeria \\ E-mail: belhennicheabdelkader@yahoo.com / a_belhenniche@esc-alger.dz \\ sfyabenahmed@yahoo.fr /sfya.ghamnia@enp-oran.dz \\ **SYSTEC -Research Center for Systems and Technologies, Faculty of Electrical Engineering, \\ Porto University, Institute for Systems and Robotics, 4200-465, Porto, Portugal \\ E-mail: flp@fe.up.pt
}

\begin{abstract}
In this article, we apply methods of fixed point theory to investigate a Lambda policy iteration with a randomization algorithm for mappings that are merely weak contractions. As simple examples show, this class of mappings provide a much wider scope than the one afforded by strong contractions usually considered in the literature. More specifically, we investigate the properties of reinforcement learning procedures which have been developed for feedback control, in the framework of fixed point theory. Under fairly general assumptions, we determine sufficient conditions for the convergence with probability one in infinite dimensional policy spaces.

Key Words and Phrases: Fixed point theory, weakly contractive map, Lambda policy iteration with randomization.
\end{abstract}

2020 Mathematics Subject Classification: 47H10, 90C30, 49L20.

Acknowledgment. This work is supported by grant of the ministry of Higher Education and Scientific Research of Algeria, project number: 685/PNE/Enseignant/ Chercheur/Portugal/2019-2020, awarded to Abdelkader Belhenniche. This work is supported by the R\&D Unit SYSTEC, ref. POCI-010145-FEDER-006933 funded by ERDF - COMPETE2020 - FCT (Foundation for Science and Technology)/MEC PT2020, Project STRIDE, ref. NORTE-01-0145FEDER-000033, funded by ERDF NORTE 2020, and Project HARMONY, ref.AAC n2/SAICT/2017 — 031411, funded by FCT/MEC - ERDF - COMPETE2020

\section{REFERENCES}

[1] M. Abbas, H. Iqbal, A. Petruşel, Fixed points for multivalued Suzuki type $(\theta, \mathcal{R})$-contraction mapping with applications, Journal of Function Spaces, 2019(2019).

[2] Y.I. Alber, Recurrence relations and variational inequalities, Doklady Akademii Nauk. Russian Academy of Sciences, 270(1983), no. 1, 11-17.

[3] Y.I. Alber, S. Guerre-Delabriere, Principle of weakly contractive maps in Hilbert spaces. New Results in Operator Theory and its Applications, Birkhäuser, Basel, 1997, 7-22. 
[4] A. Arutyunov, V. Jakimovic, F. Pereira, Second order necessary conditions for optimal impulsive control problems, Journal of Dynamical and Control Systems, 9(2003), no. 1, 131-153.

[5] A. Arvanitakis, A proof of the generalized Banach contraction conjecture, Proceedings of the American Mathematical Society, 131(2003), no. 12, 3647-3656.

[6] R. Bellman, The Theory of Dynamic Programming, Rand Corporation Report P-550, Santa Monica, CA, 1954.

[7] D. Bertsekas, Dynamic Programming and Optimal Control, Athena Scientific, Belmont, MA, 1995.

[8] D.P. Bertsekas, Abstract Dynamic Programming, Athena Scientific, Belmont, Massachusetts, 2013.

[9] D.P. Bertsekas, Abstract Dynamic Programming, Athena Scientific, 2018.

[10] D.P. Bertsekas, Proximal algorithms and temporal difference methods for solving fixed point problems, Computational Optimization and Applications, 70(2018), no. 3, 709-736.

[11] D.P. Bertsekas, S. Ioffe, Temporal differences-based policy iteration and applications in neurodynamic programming, Lab. for Info. and Decision Systems Report LIDS-P-2349, 1996.

[12] D.P. Bertsekas, J.N. Tsitsiklis, Neuro-Dynamic Programming, Athena Scientific, 1996.

[13] D.W. Boyd, J.S. Wong, On nonlinear contractions, Proceedings of the American Mathematical Society, 20(1969), no. 2, 458-464.

[14] B.S. Choudhury, N. Metiya, M. Postolache, A generalized weak contraction principle with applications to coupled coincidence point problems, Fixed Point Theory and Applications, 2013(2013), no. 1, 152.

[15] G. Durmaz, Some theorems for a new type of multivalued contractive maps on metric space, Turkish Journal of Mathematics, 41(2017), no. 4, 1092-1100.

[16] G. Durmaz, I. Altun, A new perspective for multivalued weakly picard operators, Publications de l'Institut Mathematique, 101(2017), no. 115, 197-204.

[17] P.N. Dutta, B. Choudhury, S. Binayak, A generalization of the contraction principle in metric spaces, Fixed Point Theory and Applications, 2008(2008), no. 1, 406368.

[18] S. Fraga, F. Pereira, Hamilton-Jacobi-Bellman equation and feedback synthesis for impulsive control, IEEE Transactions on Automatic Control, 57(2012), no. 1, 244-249.

[19] H.A. Hancer, A. Hatice, G. Mina, I. Altun, On a broad category of multivalued weakly Picard operators, Fixed Point Theory, 18(2017), no. 1, 229-236.

[20] D. Karamzin, V. De Oliveira, F. Pereira, G. Silva, On some extension of optimal control theory, European Journal of Control, 20(2014), no. 6, 284-291.

[21] M. Kikkawa, T. Suzuki, Three fixed point theorems for generalized contractions with constants in complete metric spaces, Nonlinear Analysis: Theory, Methods and Applications, 59(2008), no. 9, 2942-2949.

[22] D.E. Kirk, Optimal Control Theory: An Introduction, 1970, Prentice-Hall, Englewood Cliffs, NJ, 3(1998), 417-442.

[23] Y. Li, K.H. Johansson, J. Martensson, Lambda-Policy Iteration with Randomization for Contractive Models with Infinite Policies: Well Posedness and Convergence (Extended Version), arXiv preprint:1912.08504, 2019.

[24] S. Massa, Convergence of an iterative process for a class of quasi-nonexpansive mappings, Boll. U.M.I., 51-A(1978), 154-158.

[25] J. Merryfield, B. Rothschild, JR.J. Stein, An application of Ramsey's theorem to the Banach contraction principle, Proceedings of the American Mathematical Society, 130(2002), no. 4, 927-933.

[26] S.B. Nadler, Multi-valued contraction mappings, Pacific Journal of Mathematics, 30(1969), no. $2,475-488$.

[27] B.E. Rhoades, A comparison of various definitions of contractive mappings, Transactions of the American Mathematical Society, 226(1977), 257-290.

[28] B.E. Rhoades, Some theorems on weakly contractive maps, Nonlinear Analysis: Theory, Methods and Applications, 47(2001), no. 4, 2683-2693.

[29] M. Sniedovich, Dynamic Programming: Foundations and Principles, CRC Press, 2010. 
[30] T. Suzuki, A generalized Banach contraction principle that characterizes metric completeness, Proceedings of the American Mathematical Society, 136(2008), no. 5, 1861-1869.

Received: May 16, 2020; Accepted: November 29, 2020. 
A. BELHENNICHE, S. BENAHMED AND F.L. PEREIRA 